\title{
E्द्धreatidaro
}

\section{Autoria, Intervenções e Deslocamento Cultural: uma análise intercultural}

Damaris Fabiane Storck Henrique Evaldo Janzen

RESUMO - Autoria, Intervenções e Deslocamento Cultural: uma análise intercultural. Este artigo apresenta uma análise intercultural a partir das concepções bakhtinianas de linguagem, do livro didático de língua inglesa, Keep in Mind, aprovado pelo PNLD - 2011. As três categorias de análise utilizadas neste trabalho - duplicação do outro, construções híbridas e exotopia - expressam os movimentos de aproximação das autoras com a cultura escolar e estão centradas especificamente em um objetivo: identificar no livro didático momentos que evidenciam os processos de deslocamento cultural das autoras durante a elaboração do livro, para então entender suas relações, mediante os critérios avaliativos do PNLD.

Palavras-chave: Autoria. Livro Didático. Deslocamento Cultural.

ABSTRACT - Authorship, Interventions and Cultural Dislocation: an intercultural analysis. This article presents an intercultural analysis from bakhtinian conception of language of the English text book Keep in Mind approved by PNLD - 2011. The three categories of analysis used in this paper - duplication of the other, hybrid constructions and exotopy - express the movements of the approximation between authors and school culture and have an specific aim: identify some evidence of the author's cultural dislocation during the elaboration of the book, to understand the relations between the authorship and the evaluate criterions of PNLD.

Keywords: Authorship. Text Book. Cultural Dislocation.

Educação \& Realidade, Porto Alegre, v. 38, n. 1, p. 319-337, jan./mar. 2013.

Disponível em: <http://www.ufrgs.br/edu_realidade> 
Autoria, Intervenções e Deslocamento Cultural

\section{Introdução}

O Programa Nacional de Livros Didáticos - PNLD - é uma política do Ministério da Educação, que tem como objetivo a compra e a distribuição de livros gratuitos para todos os alunos do Ensino Fundamental das escolas da rede pública do Brasil. Apesar de já estar em execução há cerca de dez anos, esta é a primeira vez que o componente curricular de Língua Estrangeira Moderna (LEM), de Inglês e Espanhol, passou a fazer parte do programa, chegando às escolas no ano de 2011.

Nessa primeira edição, vinte e seis coleções de língua inglesa foram inscritas no processo seletivo das obras didáticas, mas apenas duas corresponderam aos critérios requisitados pelas normas do PNLD: Keep in Mind ${ }^{1}$; e Links - English for Teens ${ }^{2}$.

Com o objetivo de compreender como os autores produziram esses livros, adequando-os às exigências do programa, buscou-se nos elementos estruturantes da interculturalidade, em diálogo com as concepções bakhtinianas de linguagem, elementos de aproximação das autoras com a cultura escolar, para comparar a sua concepção em relação ao outro - por meio de um deslocamento cultural ${ }^{3}$ - ao seu discurso, produzido no livro didático, tendo como princípio básico a questão da autoria, em meio às exigências impostas pelo PNLD.

A análise intercultural, a partir das concepções bakhtinianas de linguagem, aplica-se, neste trabalho, principalmente porque a base orientadora da relação livro e escola é de cunho cultural, e também, por considerarmos que as autoras estabelecem um movimento de deslocamento durante a elaboração do livro.

Para compreender essa aproximação entre as autoras e a cultura escolar, esta pesquisa está centrada nos trabalhos de Janzen (2005), que produz um diálogo entre Bakhtin e a interculturalidade, propondo três categorias que expressam movimentos de aproximação com a outra cultura: duplicação do outro, construções híbridas e exotopia.

Partindo do pressuposto de que o livro didático, como um gênero discursivo 4 , propaga um discurso permeado por outras vozes, nossa preocupação com relação a esse pressuposto centrou-se em uma pergunta norteadora para este trabalho: $O$ discurso das autoras, aplicado na elaboração do livro didático, em função do seu movimento de aproximação com o outro no processo de DC, estaria refletindo uma visão de livro didático baseado na concepção do autor ou apenas das exigências do PNLD?

Cabe ressaltar que, como as duas coleções aprovadas possuem um mesmo padrão, já que correspondem aos mesmos critérios avaliativos do programa, a escolha do livro didático analisado partiu de um levantamento informal, entre algumas escolas das cidades de Porto União - SC e União da Vitória - PR, no qual optou-se pela análise do livro escolhido pela maioria das escolas desse grupo: Keep in Mind. 
Como esta análise está centrada apenas no manual do professor, no qual o autor estabelece um diálogo direto com o docente, qualquer um dos volumes da coleção poderiam ter sido avaliados, tendo em vista que todos possuem orientações e são constituídos pelo mesmo conteúdo na assessoria pedagógica. No entanto, optou-se por analisar o volume destinado ao trabalho com alunos do $6^{\circ}$ ano, justamente por tratar-se do primeiro volume da coleção, que, assim como o livro didático $^{5}$, no que diz respeito ao ensino de Língua Inglesa, terá seu primeiro momento na escola.

\section{Interculturalidade}

A necessidade de aproximação e do contato com diferentes culturas ocorre, principalmente, devido aos efeitos da globalização econômica, social, cultural, das tecnologias e da comunicação.

Dessa maneira, o domínio de línguas estrangeiras, em especial o da língua inglesa, como língua franca, possibilita a integração dos indivíduos no contato com o outro e na aproximação com a outra cultura.

A interculturalidade contribui para o respeito às diferenças, tornando possível o diálogo com grupos, em diversos aspectos culturais.

Pode-se dizer que os indivíduos em uma sociedade não possuem apenas uma cultura, pois as culturas estão relacionadas. Quando o termo diversidade cultural está em questão, é provável, então, que para muitas pessoas uma relação de proximidade com o outro se aplique quase involuntariamente. Dizemos isso, porque o universo cultural abrange não apenas culturas distantes, mas princípios de relações que se manifestam, nos mais variados planos de nossas atividades. Políticas, religiões, crenças, costumes, nacionalidades etc., o contato com o outro, e o contraste com as diferenças é uma realidade bastante frequente na concepção contemporânea de interculturalidade. "Todas as culturas estão envolvidas umas com as outras; nenhuma é isolada e pura, todas são híbridas, heterogêneas e extraordinariamente diferenciadas e não monolíticas" (Said, 1993, apud Eagleton, 2005, p. 28-29).

Dessa forma, a escola, como uma instituição cultural, integrada às ideologias propostas na constituição de seu currículo escolar, estabelece um processo contínuo de desenvolvimento do indivíduo e da sociedade.

Marcada pela diversidade, diferentes culturas imergem e compartilham um mesmo espaço, em um amplo processo de interação.

É necessário reconhecer, entretanto, que a cultura não pode ser vista, nas palavras de Forquin (1993), como um "tecido uniforme e imutável” (p. 14), isto é, ela não se impõe de uma mesma forma para todos os indivíduos na sociedade, porque, dentro de um mesmo espaço restrito de sala de aula, a interculturalidade funde-se em vários níveis. Sendo assim, somos levados a pensar a respeito do que realmente deve ser en- 
Autoria, Intervenções e Deslocamento Cultural

tendido culturalmente como essencial para o ensino-aprendizagem no sistema educativo.

Para Forquin (1993), a educação escolar não fica limitada apenas a uma seleção entre os saberes e os materiais culturais disponíveis num determinado momento. Ela deve estar integrada a um trabalho de reorganização e reestruturação ou de transposição didática. "Tal é o papel, por exemplo, dos manuais e de todos os materiais didáticos, mas também o dos exercícios escolares, das lições, dos deveres, dos controles periódicos, dos sistemas de recompensas e sanções propriamente escolares" (Forquin, 1993, p. 17).

Ao trabalhar a relação autor e LD, apontamos para o encontro cultural, relevando alguns importantes aspectos referentes à questão da autoria.

Sabemos que, ao elaborar um LD destinado para o ensino-aprendizagem de língua inglesa no Ensino Fundamental, o autor deve incluir no seu trabalho as premissas que estimam os objetivos ditados pelas leis da Educação no Brasil, além de ter que conter em sua obra todos os elementos considerados indispensáveis para a veiculação desse material no âmbito escolar.

Por esse motivo, acredita-se na possibilidade de um movimento de aproximação do autor do LD com a cultura escolar, de modo que esse processo de deslocamento sirva para dar-lhe suporte no desenvolvimento do LD. No entanto, essa transposição não deve servir apenas como mera abstração dos elementos da cultura escolar. A riqueza desse movimento está na possibilidade de o autor aproximar-se dos interlocutores de seu discurso e compreendê-los a partir de seus universos culturais.

\section{A Questão da Autoria}

A questão que envolve o tema do autor e da autoria está, segundo Faraco (2009), em quase todos os textos conhecidos de Bakhtin. As relações estabelecidas entre o autor e o herói são tomadas neste trabalho para a reflexão da concepção do autor do LD e de seus interlocutores, entendidos aqui como os outros.

Mas com quem exatamente o autor dialoga? Sob quais perspectivas se determinam os valores subjacentes ao LD?

É importante destacar que o outro a quem nos referimos neste trabalho, trata-se na verdade de os outros: professores (já que este trabalho analisa apenas o manual do professor); alunos (especificamente do $6^{\circ}$ ano do Ensino Fundamental); e editores e avaliadores do MEC (que analisam e selecionam LDs de acordo com determinadas exigências).

O outro, no sentido de "outro", "outra pessoa", ou no sentido de "o outro", “o estranho”, o "alheio”, é inseparável 
do eu, e enquanto estrangeiro não pode ser englobado na totalidade do eu. O outro permanece refratário a toda categoria que queira eliminar sua alteridade e subjugá-lo à identidade do eu; além disso, o eu necessita de outro para construir seu mundo e para construir-se a si mesmo (Ponzio, 2008, p. 193).

Em seu texto O Autor e a Personagem, Bakhtin discorre sobre a diferença existente entre o autor-criador e o autor-pessoa.

Para ele o autor-pessoa é o ser, o escritor, o componente da vida. Já o autor-criador é parte da constituição do objeto-estético, "é o agente da unidade tensamente ativa do todo acabado, do todo da personagem e do todo da obra." (Bakhtin, 2003a, p. 10), o componente da obra.

O autor-criador é, assim, quem dá forma ao conteúdo: ele não apenas registra passivamente os eventos da vida (ele não é um estenógrafo desses eventos), mas, a partir de uma certa posição axiológica, recorta-os e reorganiza-os esteticamente (Faraco, 2005, p. 39).

A relação estabelecida entre o autor-pessoa e o autor-criador é, portanto, uma posição axiológica. "O autor-criador é, assim, uma posição refratada e refratante” (Faraco, 2009, p. 91). Refratada no sentido que, o autor-criador é na realidade uma constituição dos valores do autor-pessoa; e refratante "porque é a partir dela que se recorta e se reordena esteticamente os eventos da vida" (p. 91).

Segundo Bakhtin, a realização de uma atividade estética é um movimento condicionado ao autor. Trata-se do seu distanciamento do objeto, que concede a capacidade de perceber o todo da obra, para então realizar um acabamento, por meio de uma posição exotópica.

A importância de considerarmos a noção de autor como relacionada à realização de uma atividade estética, é ressaltada aqui, uma vez que a elaboração de um LD requer necessariamente a compreensão dos interlocutores e dos eventos escolares aos quais o autor se dirige. Assim, da mesma forma como na escrita literária, para o autor do LD, a alteridade "é o seu ponto de vista específico e se determina na dialética entre estar dentro e estar fora, entre participação e distanciamento” (Ponzio, 2008, p. 192).

Com isso, podemos dizer que o autor do LD escreve e dirige-se a outros, estando sempre na fronteira entre o estar de fora e o querer saber sobre os eventos que ocorrem em sala de aula.

Se pensarmos no LD como uma consequência das decisões discursivas do autor, entendemos que os valores subjacentes ao LD, foram constituídos à medida que o outro é colocado na relação intersubjetiva, sendo esse outro, então, fundamental para que o próprio eu se determine. Como um sujeito histórico e ideológico, o autor é constituído por outras vozes socias que, portanto, o tornam um ser dialógico. Assim, mesmo sendo pouco perceptível, quase sempre é possível encontrarmos as 
Autoria, Intervenções e Deslocamento Cultural

marcas da subjetividade do autor nos textos escritos ou falados. "A voz do autor concerne um lugar enunciativo e como tal ela é portadora de um olhar, de um ponto de vista que atravessa o texto do início ao fim." (Amorim, 2003, p. 77).

A subjetividade envolve pensamentos e emoções conscientes e inconscientes que constituem a compreensão que temos de nosso eu. Vale destacar, todavia, que, como essa subjetividade é vivida em um contexto social no qual a linguagem e a cultura dão significado à experiência, as posições que assumimos e com as quais nos identificamos estão em constante conflito e fluxo, o que indica que ela (a subjetividade) é fragmentada e dividida, ou seja, dilui-se na relação do eu com o outro. Essa compreensão exige, em contrapartida, que um exame da alteridade seja estabelecido na relação intersubjetiva (Oliveira, 2003, p. 531).

Sem dúvidas, acreditamos no reflexo da individualidade do autor no LD, quando o consideramos como o principal responsável pela criação das atividades, das metodologias e da construção do livro em geral. O autor é, pois, o enunciador, e como tal aplica seu discurso nas relações comunicativas com os demais interlocutores.

\section{Diálogos entre Aspectos de Interculturalidade e as Concepções Bakhtinianas de Literatura/Linguagem}

Para poder compreender o outro, por meio da alteridade, Janzen - apoiado no arcabouço teórico do Círculo bakhtiniano - propõe três categorias ${ }^{6}$ que expressam os movimentos de aproximação com o outro e com a outra cultura: duplicação do outro, construções híbridas e exotopia.

Duplicação do outro: nesta categoria o outro é percebido por meio do sistema axiológico de valores da própria cultura. Existe uma tendência em fazer um julgamento, a partir das perspectivas e parâmetros da própria cultura que pode produzir um estranhamento com relação ao outro. É uma ideia homogeneizante, na qual há uma generalização por parte de um grupo, que limita os valores da cultura alheia. "Uma visão de mundo estereotipada pode produzir graus de estranheza/distanciamento em relação à cultura-alvo" (Janzen, 2005, p. 35).

O etnocentrismo consiste do julgamento avaliativo de um determinado grupo ou indivíduo sobre a outra cultura. Essa avaliação é uma tendência que pode gerar uma visão distorcida do outro, que passa a ser visto como parte de um grupo.

A atitude etnocêntrica pode explicar a forte tendência ao pensamento unitário. Neste contexto, é emblemático os que têm tal atitude não enxergarem os indivíduos, porém apenas grupos. A diluição do outro/do sujeito, ao ser per- 
cebido apenas como grupo, indica a representação generalizante/homogeneizante do outro, que caracteriza a visão tradicional de cultura (Lewinson, 1964, apud Janzen, 2005, p. 36).

O estranhamento pode ocorrer, então, no encontro entre as diferenças e as diversidades culturais. Considerando que, nessa categoria, os valores do outro são avaliados a partir dos valores da própria cultura, tendo a julgar os determinados valores em extremos de bom ou mau, certo ou errado. "O discurso unitário e da homogeneização a partir de uma visão particular esvazia a perspectiva exotópica e a natureza dialógica do encontro cultural" (Janzen, 2005, p. 65).

$\mathrm{O}$ movimento de empatia e retorno à posição inicial esclarece o outro como não semelhante a mim. Entender a outra cultura não implica então aceitá-la, mas compreendê-la. Dessa forma, a eficácia da produção de um conhecimento referente ao outro não está na duplicação, mas, no excedente de visão, no distanciamento.

Assim como a cultura, a palavra é derivada de um momento-histórico específico. Os nossos enunciados "estão repletos de enunciados dos outros, os quais recebemos já com uma intenção de sentido e os impregnamos com nossa tonalidade valorativa e expressividade" (Janzen, 2005, p. 56).

O processo pelo qual duas vozes percorrem em um discurso é denominado por Bakhtin como construções híbridas. Sob esta perspectiva, há duas vozes que se entrecruzam dialogicamente, mas que não se misturam uma com a outra.

Construções híbridas: é um enunciado que, segundo Bakhtin (1998), pertence a um único falante, mas que compõe duas perspectivas, duas linguagens, dois ou mais enunciados em um mesmo conjunto sintático.

\begin{abstract}
Denominamos construção híbrida o enunciado que, segundo índices gramaticais (sintáticos) e composicionais, pertence a um único falante, mas onde, na realidade, estão confundidos dois enunciados, dois modos de falar, dois estilos, duas "linguagens", duas perspectivas semânticas e axiológicas. Repetimos que entre esses enunciados, estilos, linguagens, perspectivas, não há nenhuma fronteira formal, composicional e sintática: a divisão de vozes e das linguagens ocorre nos limites de um único conjunto sintático, frequentemente nos limites de uma proposição simples, frequentemente também um mesmo discurso pertence também simultaneamente às duas línguas, às duas perspectivas que se cruzam numa construção híbrida, e, por conseguinte, tem dois sentidos divergentes, dois tons (Bakhtin, 1998b, p. 110) .
\end{abstract}

A partir das concepções bakhtinianas da natureza dialógica do enunciado, pode-se dizer que construções híbridas ocorrem, quando 
Autoria, Intervenções e Deslocamento Cultural

um enunciado é construído a partir de outros enunciados que, por sua vez, possuem diferentes sistemas axiológicos, gerando então um novo enunciado com diferentes eixos de valores. "Em todo enunciado, descobriremos as palavras do outro, ocultas ou semiocultas, com graus diferentes de alteridade" (Janzen, 2005, p. 58).

$\mathrm{O}$ indivíduo produz um enunciado que entrecruza duas perspectivas: os valores da própria cultura e o universo cultural do outro.

Neste segundo estágio, o contato com a outra cultura já produz o reconhecimento de algumas marcas, "porém ainda com um certo grau de estranheza e distanciamento e não com a segurança que lhe permite o aprofundamento de sentido" (Janzen, 2005, p. 58).

O que determina as construções híbridas como associadas à relação intercultural é a noção de que, pelo encontro com o outro, podemos entrecruzar diferentes sistemas axiológicos, que podem gerar uma visão ambígua, se considerados os valores do outro perante os meus próprios.

Exotopia: é conceituada por Bakhtin, a partir de suas reflexões sobre a criação literária.

Para ele, a exotopia, o olhar de fora no tempo, lugar e sentido, é fundamental ao processo de compreender o outro. "A exotopia, o estar do lado de fora, o não coincidir com o outro, constitui uma questão fundamental na reflexão que envolve a alteridade cultural" (Janzen, 2005, p.50, grifo do autor).

Em seu texto Os Estudos Literários Hoje, Bakhtin ressalta que a cultura do outro só se revela sob o olhar de outra cultura.

\begin{abstract}
Um sentido só revela as suas profundidades encontrando-se e contactando-se com outro, com o sentido do outro: entre eles começa uma espécie de diálogo que supera o fechamento e a unilateralidade desses sentidos, dessas culturas (Bakhtin, 2003a, p. 366).
\end{abstract}

Bakhtin em O autor e a Personagem na Atividade Estética, introduz a concepção de excedente de visão. Para ele, o excedente de visão é um dos elementos fundamentais da exotopia:

Quando contemplo no todo um homem situado fora e diante de mim, nossos horizontes concretos efetivamente vivenciáveis não coincidem. Porque em qualquer situação ou proximidade que esse outro que contemplo possa estar em relação a mim, sempre verei e saberei algo que ele, da sua posição fora e diante de mim, não pode ver: as partes de seu corpo inacessíveis ao seu próprio olhar - a cabeça, o rosto, e sua expressão -, o mundo atrás dele, todo o objeto de relações que, em função dessa ou daquela elação de reciprocidade entre nós, são acessíveis a mim e inacessíveis a ele (Bakhtin, 2003a, p. 21). 
Assim, o excedente de visão permite a cada um a possibilidade de perceber o outro em uma dimensão em que esse outro não pode contemplar a si próprio.

A partir daí, para Bakhtin, o deslocamento pelo qual o indivíduo concebe os outros valores da cultura alheia deve efetivar-se sob o processo de empatia. Ou seja, de ver o outro a partir dos valores do outro, percebendo coisas que só poderão ser vistas a partir do excedente de visão.

[...] para depois retornar (através da contemplação) à posição inicial, que possibilita elaborar o seu acabamento e o do outro. Quando Bakhtin se refere a esta perspectiva exotópica na vida, ressalta que a riqueza da exotopia não está na duplicação do semelhante, porém no fato de que este outro vive (e continua vivendo) numa categoria de valores diferentes (Janzen, 2005, p. 61).

Ao contrário do acabamento dado à questão literária, entende-se que, na vida, o acabamento é sempre inconcluso. Se nos deslocamos para a cultura alheia "e não retornamos para a elaboração de uma síntese, poderemos estar apenas reproduzindo uma duplicação desta cultura”. (Janzen, 2005, p. 64) Neste caso, o acabamento não exige aceitar o outro, mas entender que esse outro vive em uma outra categoria de valores distintos.

\section{Orientações Pedagógicas}

\section{- Duplicação do Outro}

Segundo as autoras, no processo de criação e elaboração do livro, foi priorizado ao professor apoio e facilidade de uso. Para isso, considerou-se que as instruções de atividades fossem detalhadas no livro-texto, para que o professor não precisasse consultar o manual, no decorrer das aulas.

Entretanto, nessas orientações que aparecem junto às atividades do livro, sempre grafadas em azul, o autor dita ao professor como ele deve ou não proceder no trabalho com as atividades.

\section{Fragmento 1 - Orientações ao Professor}

Unit 3
Seção: Get in the mood.
Orientação do autor: Professor(a): Os focos desta atividade são esportes e núme-
ros. Pergunte aos alunos (1) quem pratica esporte, quais e por que escolheram as
modalidades praticadas; (2) quem gosta de assistir a eventos esportivos, quais e
por quê; e (3) quem não gosta nem de praticar nem de assistir e por que não. Faça
as perguntas em inglês, usando também gestos e as ilustraçães como suporte,
mas aceite que as respostas sejam dadas tanto em português como em inglês.
Fonte: Chin; Zaorob, 2009, p. 29

Educação \& Realidade, Porto Alegre, v. 38, n. 1, p. 319-337, jan./mar. 2013.

Disponível em: <http://www.ufrgs.br/edu_realidade> 
Autoria, Intervenções e Deslocamento Cultural

Percebemos, nesse fragmento, que as autoras tendem a duplicar a outra cultura. Trata-se de uma atitude relacionada ao julgamento a partir dos seus próprios valores. Observamos que algumas de suas imposições, no trabalho com as atividades, sugerem que os professores devem conduzir o processo de ensino-aprendizagem com base total e absoluta das orientações feitas por elas no LD. Trata-se de um estereótipo, em que a tendência é considerar que os professores estariam agindo a partir dessas ordens: "pergunte aos alunos", "faça as perguntas em inglês" (Chin; Zaorob, 2009, p. 29). Além disso, é possível encontrar em boa parte das orientações, em outras unidades, vários outros verbos usados no imperativo, como: explique, mostre, aponte, indique, escreva, fale, repita etc.

Num primeiro momento, aquilo que poderia representar uma concepção das autoras - obtida ou não por meio do DC - sobre a possibilidade de estar dialogando com professores cujo trabalho poderia carecer de uma boa base para efetivar o ensino, devido à má formação ou até mesmo à carência de uma formação continuada, representa, na realidade, uma homogeneização do grupo, em que todos são avaliados de maneira uniforme.

Em outras situações, percebemos também um discurso que tende à homogeneização da cultura:

Fragmento 2

Get in the mood - "Esta seção é apenas um warm-up. Procure completá-la em apenas 10 minutos."

Fonte: Chin; Zaorob, 2009, p. 53.

\section{Fragmento 3}

Act 1 Presentation - "Este é o diálogo de abertura e serve para apresentar ao alunos o conteúdo linguístico-funcional que vão aprender na Unit. Não é uma atividade de desenvolvimento da habilidade comunicativa de compreensão oral. Portanto não a aborde como tal." Fonte: Chin; Zaorob, 2009, p. 53.

Nessas passagens do livro, as orientações das autoras podem ser vistas como moldes. A expectativa de tempo estipulado para a atividade de apenas 10 minutos, cobre a possibilidade de o professor incluir nesta seção outros objetivos além dos propostos, que poderia considerar necessário para o ensino-aprendizagem. Da mesma forma ocorre com as orientações que indicam o que não deve ser feito ao trabalhar com a seção, elas estabelecem um padrão que ignora o espaço para a capacidade criativa do professor.

\section{Fragmento 4}

\section{Unit 2}

Seção: Act 2 Focus on vocabulary

- Orientação do autor: Professor (a): Mostre aos alunos que o primeiro grupo de cumprimentos é usado quando chegamos e encontramos alguém, enquanto o segundo é usado ao nos despedirmos. Explique aos alunos que good evening é usado quando encontramos alguém ao anoitecer e good night para nos despedirmos à noite.

Fonte: Chin; Zaorob, 2009, p. 21. 


\section{Fragmento 5}

\section{Unit 3}

Seção: Act 2 Focus on vocabulary

Orientação ao professor: Professor (a): O final "teen" normalmente corresponde à silaba tônica. A pronúncia correta dos números 13 a 19 facilita a diferenciação entre estes e os números 30,40 etc., que os alunos aprenderão na Unit 9.

Fonte: Chin; Zaorob, 2009, p. 31.

Nos fragmentos 4 e 5, percebe-se que, em vez de orientar o professor quanto ao objetivo de mostrar aos alunos o uso dos cumprimentos e da pronúncia correta das terminações dos números, as autoras ensinam aos professores, como se o seus conhecimentos não fossem o suficiente para trabalhar o objetivo das atividades. Esta duplicação reflete uma visão estereotipada do professor, como se ele não fosse capaz de ensinar a partir dos seus próprios conhecimentos e de sua formação. Nesta categoria, as autoras parecem estar sugerindo que o professor receberá as "ordens" e as executará de acordo com as orientações.

Entendemos que, neste primeiro movimento, as autoras tendem a projetar uma imagem fechada do professor, quando partem do universo de valores da própria cultura.

Assim a homogeneização e o estereótipo da visão do professor é uma tendência do movimento de aproximação das autoras com os seus interlocutores que, neste caso, são os professores. A visão projetada no discurso das autoras tende a um reflexo de suas próprias concepções, quando fazem o julgamento de valores partindo dos seus próprios parâmetros. Dessa forma, entendemos que a voz propagada no discurso é a voz das autoras, que reflete os seus próprios pensamentos.

\section{- Construções Híbridas}

Ao orientar os professores quanto às práticas que se aplicam à avaliação dos alunos, as autoras destacam:

\section{Fragmento 6}

Assessoria pedagógica - Avaliação.

Procure identificar o nível de interesse e participação da classe bem como o grau de sucesso das atividades ou seus pontos fracos, a fim de que sejam feitos ajustes necessários, mudando de tática e experimentando novas formas de ensinar, conforme a necessidade.

Fonte: Chin; Zaorob, 2009, p. 56.

Podemos perceber, a partir desse fragmento, que o livro entrecruza dois eixos de valores: conforme apontamos na primeira categoria (fragmentos 1-5), as autoras impõem o trabalho com as atividades, dizendo o que o professor deve ou não fazer em sala de aula, considerando que suas orientações serão vistas como moldes. Num segundo momento (fragmento 6) elas indicam que o professor pode ter autonomia para

Educação \& Realidade, Porto Alegre, v. 38, n. 1, p. 319-337, jan./mar. 2013.

Disponível em: <http://www.ufrgs.br/edu_realidade> 
Autoria, Intervenções e Deslocamento Cultural

decidir a maneira mais adequada de realizar o processo de ensino. Assim, indicamos um enunciado que entrecruza essas duas perspectivas:

\section{Fragmento 7}

Constituição dos volumes e planejamento: obviamente, estamos cientes de que essas estimativas podem não corresponder à realidade dependendo das condições de trabalho de cada professor, muitas vezes sujeitas a fatores que fogem ao seu controle. Portanto alertamos que os valores apresentados aqui servem apenas de guia. Recomendamos ao professor que conheça bem o material didático e, acima de tudo, seus alunos, a fim de decidir, em cada unidade, que atividades podem, por exemplo, ser feitas por eles fora da sala de aula ou, simplesmente, deixadas de lado em prol de outras que interessem ou atendam mais às suas necessidades. Fonte: Chin; Zaorob, 2009, p. 45.

Esse discurso que envolve um movimento que desloca as autoras num processo de aproximação com a outra cultura, no caso, a do trabalho do professor em sala de aula, evidencia a duplicação do professor, mas, também, estabelece diferentes eixos de valores.

Mesmo enxergando o professor por meio de uma visão estereotipada, percebe-se no livro um discurso que intercala a priorização do trabalho mediante as orientações pedagógicas, mas que também compreende as interações de sala de aula como parte de um processo que não se efetiva apenas como um roteiro, no qual professores e alunos atuam num espaço de acontecimentos previstos.

Ao aproximarmos a visão das autoras, ao item 13 da ficha de avaliação do PNLD, percebemos que o programa assume um dos eixos de valores propagados no discurso.

\section{Fragmento 8}

"13. O manual discute o uso adequado dos livros, inclusive no que se refere às estratégias e recursos de ensino a serem empregados, evitando detalhamentos que possam impedir a criatividade e a autonomia do professor?"

Fonte: Brasil, 2011.

Os eixos de valores entrecruzados nessa categoria são reflexos do pensamento das autoras, que consideram as orientações como um guia para o trabalho em sala de aula, e o reflexo das exigências do PNLD, quando sugere que os manuais não tirem a autonomia dos professores.

\section{- Exotopia/Acabamento}

O movimento exotópico, que estabelece o encontro por meio das orientações, pode ser identificado nas palavras das autoras, quanto à visão da obra em relação aos papéis do professor e do aluno. Identificamos, no fragmento a seguir, a exotopia, um acabamento por meio de um movimento de empatia, no qual as autoras parecem compreender a realidade dos acontecimentos de sala de aula, e também, da autonomia do professor: 


\section{Fragmento 9}

Assessoria pedagógica: Não obstante, a verdade é que estas orientações refletem o que nós faríamos, que pode ser diferente do que outros professores julgariam melhor fazer. Portanto, o importante é conhecer bem seus alunos e adequar os procedimentos necessários a eles.

Fonte: Chin; Zaorob, 2009, p. 53.

Percebemos a exotopia no excedente de visão das autoras, que parecem compreender que o professor é capaz de trabalhar com o livro, mas que também é o responsável pelos acontecimentos em sala de aula, cabendo a ele decidir sobre o que deve ou não ser trabalhado, escolhendo aquilo que, de acordo com os seus conhecimentos, deverá ser inferido no processo de ensino-aprendizagem. Esse acabamento, podese dizer, é uma tendência da divisão de valores que partiu da segunda categoria, sob um olhar fragmentado do processo de DC.

\section{Fragmento 10}

...o professor sai do centro do palco, de onde conduzia todas as atividades didáticas, para desempenhar o papel de facilitador do processo de comunicação e das tarefas. Porém ele é também um dos integrantes na classe e o parceiro mais competente. Como tal, fornece os insumos necessários, demonstra atividades, analisa necessidades e ajuda os alunos a superarem os obstáculos que encontrarem nos processos de comunicação e aprendizagem e dá feedback ${ }^{7}$. Fonte: Chin; Zaorob, 2009, p. 16.

Assim, fica evidenciada a realização de um movimento exotópico, que concede às autoras uma compreensão mais completa e abrangente da outra cultura. As autoras fazem o acabamento, constatando que suas orientações não serão as únicas fontes de realização do processo de ensino-aprendizagem.

Cabe destacar que, ao realizar o acabamento, as autoras não tiveram necessariamente uma empatia em relação ao outro. Pelo contrário, a partir da divisão de valores que indicamos na segunda categoria, entendemos que o discurso propagado na realização do acabamento refletiu a voz do PNLD.

\section{Constituição dos Volumes e Planejamento do LD}

\section{- Duplicação do outro}

Na seção destinada ao esclarecimento da organização e do planejamento do LD, as autoras fazem a seguinte constatação:

\section{Fragmento 11}

Constituição dos volumes e planejamento: Quanto aos números de aulas e horas de trabalho, consideramos que o público-alvo terá duas aulas de 50 minutos cada por semana durante o ano letivo. Estimamos que o professor conseguirá cobrir a Welcome, as Reviews e as tematic units em uma aula cada; e que concluirá o trabalho com as Units do $3^{\circ}$ ciclo em 3-4 aulas e as do $4^{\circ}$ ciclo em 4-5 aulas cada. 
Autoria, Intervenções e Deslocamento Cultural

\begin{tabular}{|c|c|c|c|c|c|}
\hline \multicolumn{6}{|c|}{$3 .^{\circ}$ ciclo: Volumes 1 e 2} \\
\hline Qtd. & Componentes & $\begin{array}{l}\text { Aulas de } \\
50 \text { min. } \\
\text { (mínimo) }\end{array}$ & $\begin{array}{l}\text { Aulas de } \\
50 \text { min. } \\
\text { (máximo) }\end{array}$ & $\begin{array}{c}\text { Semanas } \\
2 \text { aulas } \\
\text { (mínimo) }\end{array}$ & $\begin{array}{c}\text { Semanas } \\
2 \text { aulas } \\
\text { (máximo) }\end{array}$ \\
\hline 1 & Welcome & $1 \times 1=1$ & $1 \times 1=1$ & & \\
\hline 16 & Unit+Extra & $3 \times 16=48$ & $4 \times 16=64$ & & \\
\hline 8 & Review & $1 \times 8=8$ & $1 \times 8=8$ & & \\
\hline 4 & $\begin{array}{c}\text { Thematic } \\
\text { unit }\end{array}$ & $1 \times 4=4$ & $1 \times 4=4$ & & \\
\hline \multirow[t]{5}{*}{4} & Avaliação & $1 \times 4=4$ & $1 \times 4=4$ & & \\
\hline & Aulas/volume & 65 & 81 & 30,5 & 40,5 \\
\hline & $\begin{array}{l}\text { Horas/ } \\
\text { volume }\end{array}$ & $54-55$ & $67-68$ & & \\
\hline & $\begin{array}{c}\text { Aulas/ } \\
3 .^{\circ} \text { ciclo }\end{array}$ & 130 & 162 & 65 & 81 \\
\hline & $\begin{array}{l}\text { Horas/ } \\
3 .^{\circ} \text { ciclo }\end{array}$ & $108-110$ & $134-136$ & & \\
\hline
\end{tabular}

Sem dúvida, o planejamento é um elemento importante para direcionar o autor no desenvolvimento do LD, além de facilitar o trabalho do professor em sala de aula. No entanto, as estimativas das autoras na elaboração do LD podem ser vistas sob a perspectiva de uma visão rígida e estereotipada dos eventos escolares. Entendemos que a tendência a considerar as horas/aulas em relação às unidades e atividades propostas correspondem à aproximação das autoras aos interlocutores dos seus discursos. No entanto, percebemos, nesse processo, o primeiro movimento do DC que, por sua vez, duplica os eventos escolares.

\section{- Construções Híbridas}

Ao realizarmos uma aproximação entre os critérios avaliativos do PNLD (fragmento 12) e o discurso das autoras, destacado na primeira fase (fragmento 11), percebemos alguns indícios do segundo movimento do DC:

\section{Fragmento 12 - Ficha de Avaliação do PNLD}

III Coerência e adequação entre abordagem teórico-metodológica assumida pela coleção e a proposta didático-pedagógica e objetivos explicitados: "7. A obra organiza-se - tanto do ponto de vista dos volumes que a compõem, quanto das unidades estruturadoras de cada um de seus volumes - de forma a garantir a progressão do processo de ensino-aprendizagem, especialmente em relação a tópicos linguísticos, temas e atividades?"

Fonte: Brasil, 2010 
Conforme explicitado neste fragmento, o planejamento é uma exigência para as obras didáticas.

No entanto, identificamos algumas atividades do livro, que comportam duas perspectivas. Por um lado o livro é estruturado de acordo com o PNLD, por outro, percebe-se que as autoras não creditam a estruturação elaborada no livro como uma diretriz absoluta para o trabalho de sala de aula.

O LD, portanto, apresenta dois eixos: é estruturado e corresponde às estimativas do PNLD, no entanto, reflete, em alguns momentos, uma visão mais aberta que leva em consideração o ambiente escolar, não como um local que gera acontecimentos previsíveis, mas como propício e aberto às mais diversas decorrências, nos mais variados aspectos.

\section{Fragmento 13}

English in the classroom: A página consiste de uma atividade que representa aos alunos pequenas frases correspondentes às instruç̃es normalmente usadas no âmbito da sala de aula e na coleção, como "Listen to the CD.", "Read page 3." E assim por diante. Ela termina com uma orientação para os alunos recorrerem a ela como material de consulta caso tenham alguma dificuldade em entender as instruções do livro.

Fonte: Chin; Zaorob, 2009, p. 52.

A seção "English in the classroom" não está integrada ao sumário do livro, nem mesmo consta como uma atividade regular. Essa seção aparece apenas nas orientações pedagógicas que incorporam as considerações finais do LD.

"Nota-se que as referidas páginas não fazem parte da Welcome ou de nenhuma outra Unit. O professor tem a liberdade de decidir quando aplicar as atividades nelas contidas" (Chin; Zaorob, 2009, p. 52).

Outros momentos não previstos no planejamento integram a noção de que as unidades não serão tratadas exatamente como em um cronograma. Há diversos fatores que podem determinar as mais variadas situações não previstas em sala de aula. Ou seja, mesmo tratando o LD como uma estrutura previamente estabelecida, as autoras mostram que há, no decorrer das atividades, a possibilidade de adaptações e escolhas que vão além das atividades planejadas sob o enfoque de momentos previamente organizados.

O Project, por exemplo, é uma atividade extraclasse que compõe todas as unidades do livro e, portanto, corresponde ao planejamento das unidades. Contudo encontramos nas orientações pedagógicas a seguinte constatação:

A coleção propõe um projeto por Unit. Porém, nem sempre os alunos dispõem de tempo para fazer tudo. O professor pode, então, estabelecer um número mínimo de projetos por ano ou semestre e deixar que cada aluno escolha o que fazer (Chin; Zaorob, 2009, p. 56).

Educação \& Realidade, Porto Alegre, v. 38, n. 1, p. 319-337, jan./mar. 2013. 
Autoria, Intervenções e Deslocamento Cultural

As autoras dão liberdade ao professor para utilizar as atividades de "project", conforme o tempo disponível. Ou seja, o número de "projects" em relação ao desenvolvimento dessa atividade pode variar de um professor para outro, de uma turma para outra e assim por diante. As autoras "compreendem" que o tempo, e as condições de trabalho com tais atividades não será o mesmo para todos os professores, escolas e alunos. Os eventos escolares não podem estar, portanto, baseados especificamente em um cronograma.

\section{- Exotopia/Acabamento}

Identificamos o terceiro movimento do DC, que realiza um acabamento visível das autoras, em relação aos aspectos da organização e do planejamento, por meio de uma postura exotópica:

\section{Fragmento 14}

Constituição dos volumes e planejamento: Obviamente, estamos cientes de que essas estimativas podem não corresponder à realidade dependendo das condições de trabalho de cada professor, muitas vezes sujeitas a fatores que fogem ao seu controle. Portanto, alertamos que os valores apresentados aqui servem apenas de guia. Recomendamos ao professor que conheça bem o material didático e, acima de tudo, seus alunos, a fim de decidir, em cada unidade, que atividades podem, por exemplo, ser feitas por eles fora da sala de aula ou simplesmente deixadas de lado em prol de outras que interessem ou atendam mais às suas necessidades. Fonte: Chin; Zaorob, 2009, p. 45.

Com essa constatação, percebemos que as autoras contemplam por meio de um movimento exotópico, que os eventos de sala de aula não sejam compreendidos como situações previsíveis, mas como sujeitas aos acontecimentos e situações ocasionais decorrentes da cultura escolar.

As vozes das autoras estão demarcadas no discurso que contempla o acabamento nessa categoria. Entendemos que esse acabamento não reflete a voz do PNLD, ou seja, trata-se de uma constatação que foi entendida a partir do próprio movimento de DC.

\section{Considerações Finais}

Quando realizam o primeiro movimento do descolamento, as autoras tendem à visão duplicadora. Embora essa visão propague um estereótipo da outra cultura, é em meio a esse discurso que percebemos, em sua intimidade, aquilo que na verdade revelaria as suas opiniões. Nessa primeira fase do DC, percebemos um discurso que reporta uma opinião, uma visão, uma ideia, e até mesmo uma concepção de ensino que reflete uma subjetividade que, de certa forma, corresponde apenas às próprias autoras, isto é, à voz das autoras. 
Quando contemplamos a segunda fase do DC, damos como referência à elaboração do LD, os critérios avaliativos do PNLD. Da mesma forma como ocorrem nas relações interculturais, o discurso das autoras é percebido sob duas diferentes perspectivas. Em meio a essa situação, podemos ouvir a voz das autoras associadas à voz do programa. Nesse momento, percebemos, então, duas vozes entrecruzadas e ecoadas por meio de um discurso com eixos de valores distintos, os quais se denominam construções híbridas. As duas perspectivas estão tão bem demarcadas que é possível identificarmos o que seriam as vozes das autoras e do PNLD.

Conforme apresentado na análise, as próprias exigências do programa constituem, ao todo, a segunda fase do DC. As vozes do PNLD não estão ocultas nos enunciados das autoras, e podem ser ouvidas, quando aproximadas da visão de ensino que destacamos na primeira fase.

A terceira fase do DC, isto é, o acabamento, é o ponto de partida para que se possa dar à pergunta norteadora deste trabalho, uma conclusa resposta.

Em resposta a essa pergunta, podemos dizer que constatamos, a partir desta pesquisa, que o discurso das autoras propagado pelo LD não é apenas uma consequência do DC, isto é, trata-se de um confronto entre eixos de valores distintos, provenientes de duas perspectivas sobre um mesmo objetivo. Percebemos um discurso híbrido, que comporta a visão das autoras como escritoras do LD, mas, que também reflete a voz do PNLD, quando determina algumas exigências.

Essas duas diretrizes revelam um LD que compartilha de algumas escolhas, de algumas determinações e de formas similares de pensar o processo de ensino-aprendizagem, mas que também se adapta a outras opiniões, cedendo, em alguns casos, à palavra ao outro.

A autoria é, nesse caso, uma relação que envolve não apenas atos subjetivos das autoras do LD, mas escolhas, iniciativas e decisões que vão além de uma única voz. Ela não se encontra apenas sob pensamentos isolados da autonomia daquele que escreve, ela é na realidade uma troca de relações múltiplas em constante adaptação e/ou consentimentos.

Levando em consideração a análise das categorias, percebemos que o LD não reproduz apenas o eco do PNLD. Isto é, há uma posição das autoras, que por vezes está em desacordo com as exigências do programa. Mas o fato é que o LD enquadra-se, em todos os aspectos avaliados, e, apenas por esse motivo, é que nossa constatação revela que o LD, em si, é construído a partir de discursos híbridos. 
Autoria, Intervenções e Deslocamento Cultural

\section{Notas}

1 CHIN, Elizabeth Young; ZAOROB, Maria Lúcia F.A. Keep in Mind. São Paulo: Scipione, 2009.

2 MARQUES, Amadeu O. C. C.; SANTOS, Denise M. Links - English for Teens. São Paulo: Ática, 2009.

3 Doravante DC.

4 A importância de se considerar o livro didático como um gênero discursivo, nesse trabalho, está baseada na condição do livro como um gênero padronizado e adequado a determinados padrões, no qual acreditamos ser possível demarcar, a partir de seus enunciados, não apenas os reflexos do pensamento do autor, mas também, outras vozes que circulam e se entrecruzam na constituição do livro.

5 Doravante LD.

6 Vale destacar que essas categorias são propostas nos trabalhos desse autor, a partir das teorias de Bakhtin e Thodorov. Entretanto, neste trabalho, considerase apenas a teoria de Bakhtin.

7 Grifo nosso.

\section{Referências}

AMORIM, Marilia. Silêncio e Voz - duas ocorrências de alteridade no texto de pesquisa em Ciências Humanas e Sociais. In: INTERNATIONAL BAKHTIN CONFERENCE, 11., Curitiba, 2003. Anais... Curitiba: UFPR, 2003.

BAKHTIN, Mikhail. Estética da Criação Verbal. São Paulo: Martins Fontes, 2003a.

BAKHTIN, Mikhail. Questões de Literatura e de Estética: a teoria do romance. São Paulo: UNESP, 1998b.

BRASIL. Ministério da Educação. Secretaria de Educação Fundamental. Parâmetros Curriculares Nacionais: introdução aos parâmetros curriculares nacionais. Brasília: MEC/SEF, 1997.

BRASIL. Ministério da Educação. Guia de Livros Didáticos: PNLD 2011. Brasília: MEC, 2010.

CHIN, Elizabeth Young; ZAOROB, Maria Lúcia F. A. Keep in Mind. São Paulo: Scipione, 2009.

EAGLETON, Terry. A Ideia de Cultura. São Paulo: Editora UNESP, 2005.

FARACO, Carlos Alberto. Linguagem \& Diálogo: as ideias linguísticas do Círculo de Bakhtin. São Paulo: Parábola Editorial, 2009.

FOURQUIN. Jean-Claude. Escola e Cultura: as bases sociais e epistemológicas do conhecimento escolar. Porto Alegre: Artes Médicas Sul, 1993.

JANZEN, Henrique Evaldo. O Ateneu e Jakob von Gunten: um diálogo intercultural possível. 2005. Tese (Doutorado em Língua e Literatura Alemã) - Programa de Pós-Graduação em Língua e Literatura Alemã, Faculdade de Filosofia, Letras e Ciências Humanas, Universidade de São Paulo, São Paulo, 2005.

LARAIA, Roque. Cultura: um conceito antropológico. 18. ed. Rio de Janeiro: Jorge Zahar Ed., 2005. 
OLIVEIRA, Maria do Socorro. Escrita e Autoria entre Dois Pontos: subjetividade e alteridade. In: INTERNATIONAL BAKHTIN CONFERENCE, 11., 2003, Curitiba. Anais... Curitiba: UFPR. 2003. P. 530-534.

PONZIO, Augusto. A Revolução Bakhtiniana: o pensamento de Bakhtin e a ideia contemporânea. São Paulo: Contexto, 2008.

VOLOCHINOV, Valentin; BAKHTIN, Mikhail. Discurso na Vida e Discurso na Arte (Sobre Poética Sociológica). Tradução de Cristovão Tezza e Carlos Alberto Faraco (para fins didáticos). Título Original: Discourse in Life and Discourse in Art-Concerning Sociological Poetics. Publicado em V.N. Voloshinov, Freudism, New York: Academic Press, 1976.

Damaris Fabiane Storck é formada em Letras Português Inglês pela Faculdade Estadual de Filosofia Ciências e Letras - FAFI (2007) em União da Vitória, Paraná; Mestrado em Educação na linha de pesquisa Cultura, Escola e Ensino pela Universidade Federal do Paraná (2011); Bolsista CAPES. País: Brasil. Curitiba/ Paraná.

E-mail: dama.storck@gmail.com

Henrique Evaldo Janzen é doutor em Língua e Literatura Alemã pela Universidade Estadual de São Paulo (USP). Pós-doutor pela Universidade Federal do Rio Grande do Sul. Professor do Programa de Pós-Graduação em Educação da Universidade Federal do Paraná - UFPR. País: Brasil. Curitiba/ Paraná.

E-mail: henrijan@uol.com.br 